\title{
Heme Oxygenase-1 Induction and Organic Nitrate Therapy: Beneficial Effects on Endothelial Dysfunction, Nitrate Tolerance, and Vascular Oxidative Stress
}

\author{
Andreas Daiber, ${ }^{1}$ Matthias Oelze, ${ }^{1}$ Philip Wenzel, ${ }^{1,2}$ Franziska Bollmann, ${ }^{3}$ \\ Andrea Pautz, ${ }^{3}$ and Hartmut Kleinert ${ }^{3}$ \\ ${ }^{1}$ 2nd Medical Clinic, Department of Cardiology, University Medical Center of the Johannes Gutenberg University, \\ 55131 Mainz, Germany \\ ${ }^{2}$ The Center for Thrombosis and Hemostasis, University Medical Center of the Johannes Gutenberg University, 55131 Mainz, Germany \\ ${ }^{3}$ Department of Pharmacology, University Medical Center of the Johannes Gutenberg University, 55131 Mainz, Germany
}

Correspondence should be addressed to Andreas Daiber, daiber@uni-mainz.de

Received 27 October 2011; Accepted 21 November 2011

Academic Editor: David E. Stec

Copyright () 2012 Andreas Daiber et al. This is an open access article distributed under the Creative Commons Attribution License, which permits unrestricted use, distribution, and reproduction in any medium, provided the original work is properly cited.

Organic nitrates are a group of very effective anti-ischemic drugs. They are used for the treatment of patients with stable angina, acute myocardial infarction, and chronic congestive heart failure. A major therapeutic limitation inherent to organic nitrates is the development of tolerance, which occurs during chronic treatment with these agents, and this phenomenon is largely based on induction of oxidative stress with subsequent endothelial dysfunction. We therefore speculated that induction of heme oxygenase1 (HO-1) could be an efficient strategy to overcome nitrate tolerance and the associated side effects. Indeed, we found that hemin cotreatment prevented the development of nitrate tolerance and vascular oxidative stress in response to chronic nitroglycerin therapy. Vice versa, pentaerithrityl tetranitrate (PETN), a nitrate that was previously reported to be devoid of adverse side effects, displayed tolerance and oxidative stress when the HO-1 pathway was blocked pharmacologically or genetically by using $\mathrm{HO}-1^{+/-}$ mice. Recently, we identified activation of Nrf2 and HuR as a principle mechanism of HO-1 induction by PETN. With the present paper, we present and discuss our recent and previous findings on the role of HO-1 for the prevention of nitroglycerin-induced nitrate tolerance and for the beneficial effects of PETN therapy.

\section{Organic Nitrate Therapy and Side Effects}

Nitroglycerin (GTN) has been one of the most widely used anti-ischemic drugs for more than a century. Given acutely, organic nitrates are excellent agents for the treatment of stable effort angina, acute myocardial infarction, chronic congestive heart failure, pulmonary edema, and severe arterial hypertension (for review see $[1,2]$ ). The chronic efficacy of nitrates, however, is blunted due to the development of nitrate tolerance and endothelial dysfunction, phenomena that are largely associated with increased vascular oxidative stress (for review see [1-5]). Oxidative stress was demonstrated to be a hallmark of most cardiovascular diseases [6]. The term oxidative stress defines a state with either increased formation of reactive oxygen and nitrogen species (RONS) and/or impaired cellular antioxidant defense system (e.g., downregulation of important antioxidant proteins) with subsequent depletion of low-molecular-weight antioxidants and a shift in the cellular redox balance. The central role of the endothelium for the regulation of vascular tone makes it a vulnerable target for RONS which can interfere at many positions with the NO/cGMP signaling cascade [7].

It is well established that most organic nitrates cause nitrate tolerance and/or cross-tolerance to endotheliumdependent vasodilators (e.g., acetylcholine) [8-11]. The first report on a role for oxidative stress in the development of nitrate tolerance was published in 1995 by Münzel and coworkers for nitroglycerin therapy [12]. These authors found that superoxide levels were twofold higher in aortic 
segments from nitrate tolerant vessels with intact endothelium. Based on these findings, they suspected that the enhanced levels of superoxide in nitroglycerin tolerant vessels might contribute not only to nitroglycerin tolerance, but also to cross-tolerance to 3-morpholinosydnonimine (Sin-1) and endogenous NO production stimulated by acetylcholine. To test this hypothesis, they examined the effects of bovine $\mathrm{Cu}$, $\mathrm{Zn}$-superoxide dismutase (SOD) entrapped in $\mathrm{pH}$ sensitive liposomes. In nitroglycerin-tolerant aortic segments with endothelium, liposomal SOD markedly enhanced the relaxations evoked by nitroglycerin, Sin-1, and acetylcholine. The source of RONS formation in the setting of nitrate tolerance was first found to be NADH oxidase. This finding was mainly based on the observation that the superoxide signal was most pronounced in the presence of NADH and that it was located in the particulate and not cytosolic fraction [13]. More compelling data came from the observation that the protein kinase $\mathrm{C}$ inhibition effectively suppressed nitroglycerin-induced vascular RONS formation and vasoconstrictor supersensitivity in tolerant vessels, keeping in mind that protein kinase $\mathrm{C}$ activates $\mathrm{NADPH}$ oxidase [14, $15]$.

Since nitroglycerin is thought to release NO and induce superoxide formation simultaneously, the formation of peroxynitrite from the reaction of $\mathrm{NO}$ and superoxide could be expected. Indeed, some studies have reported on increased levels of tyrosine-nitrated proteins, which is a marker for increased peroxynitrite formation in tissue from nitratetolerant animals [16]. We could also identify higher concentrations of nitrated prostacyclin synthase and decreased prostacyclin levels in these animals [17]. Indirect proof for a role of peroxynitrite for nitrate tolerance came from the observation that hydralazine, which efficiently improves nitrate tolerance, is a powerful peroxynitrite scavenger and inhibitor of protein tyrosine nitration [18]. Moreover, authentic or in situ generated (Sin-1-derived) peroxynitrite was most efficient in inhibiting the bioactivating enzyme of nitroglycerin [19]. In addition, three independent reports provided data that peroxynitrite plays a central role in the development and pathogenesis of nitrate tolerance [20-22].

The concept of $\mathrm{NAD}(\mathrm{P}) \mathrm{H}$ oxidase-driven RONS formation as the most important source of oxidative stress in nitrate tolerance was accepted for almost 10 years. In 2004, we reported for the first time on mitochondrial ROS formation in nitroglycerin induced tolerance [23], although bioactivation of nitroglycerin by mitochondrial aldehyde dehydrogenase (ALDH-2) was already reported 2 years earlier [24]. Despite the fact that the harmful effects of organic nitrates on mitochondria have already been described in the 1960s by Needleman and coworkers (mitochondrial swelling, thiol depletion, and impaired respiration) $[25,26]$, it took more than 40 years to reveal the pivotal role of mitochondria in nitroglycerin toxicity $[23,24,27]$. To test this hypothesis, we used mice with heterozygous Mn-SOD deficiency (Mn$\mathrm{SOD}^{+/-}$), which is the mitochondrial isoform of superoxide dismutases $[28,29]$. Nitroglycerin-driven vascular and mitochondrial ROS formation was increased in $\mathrm{Mn}-\mathrm{SOD}^{+/-}$ mice, and, vice versa, the ALDH-2 activity in these samples was decreased by nitroglycerin in a more pronounced manner. Moreover, nitroglycerin potency was significantly impaired in response to low-dose nitroglycerin in vivo treatment indicating the development of nitrate tolerance by this low dose in $\mathrm{Mn}-\mathrm{SOD}^{+/-}$mice but not in wildtype controls. The detrimental role of mitochondrial RONS formation for the development of GTN-induced nitrate tolerance was further supported by a subsequent report on the prevention of GTN side effects by the mitochondriatargeted antioxidant mitoquinone (mitoQ) [30].

\section{Effects of HO-1 Induction and Suppression on Nitrate Tolerance and Oxidative Stress}

With a previous study, we demonstrated that chronic nitroglycerin (GTN) therapy results in impaired vasodilatory potency of GTN (nitrate tolerance) and of the endotheliumdependent vasodilator acetylcholine (endothelial dysfunction) as well as increased vascular and mitochondrial RONS formation [31]. Since another organic nitrate (PETN) was previously described to be devoid of nitrate tolerance and induction of oxidative stress due to induction of the heme oxygenase-1 (HO-1) system [35, 36], we hypothesized that pharmacological activation of the HO-1 system may be suitable to prevent GTN-dependent side effects. In deed, cotreatment of GTN-infused rats with the potent HO-1 inducer hemin completely prevented nitrate tolerance (restored the GTN-dependent relaxation), restored NO/cGMP signaling, increased the activity of the GTN bioactivating enzyme ALDH-2, and suppressed the mitochondrial RONS formation (Figures 1(a)-1(c)) [31]. The HO-1 product bilirubin suppressed GTN-induced RONS formation in isolated heart mitochondria (Figure 1(d)). To test the essential role of HO-1 for the tolerance devoid action of PETN, we cotreated PETN-infused rats with the HO- 1 suppressor apigenin and observed a tolerance-like phenomenon displaying impaired PETN-dependent relaxation, disturbed NO/cGMP signaling, and increased mitochondrial RONS formation (Figures 1(e)$1(\mathrm{f}))[31]$.

These observations are in good accordance with previous reports on $\mathrm{HO}-1$ induction by statins $[37,38]$ and prevention of nitrate tolerance in GTN-infused experimental animals [39] as well as human individuals [40, 41]. The role of HO-1 for prevention of organic nitrate induced tolerance, endothelial dysfunction, and oxidative stress is further supported by observations that the HO- 1 product bilirubin efficiently scavenged GTN-induced RONS (most probably peroxynitrite) formation in isolated mitochondria $[29,31]$. Likewise, the HO-1 products bilirubin and carbon monoxide as well as PETN increased the expression of the GTP-cyclohydrolase-1 (GCH-1), the most important enzyme for de novo synthesis of tetrahydrobiopterin $\left(\mathrm{BH}_{4}\right)$, an essential cofactor for endothelial NO synthase (eNOS) function $[34,42]$. In contrast, GTN in vivo therapy decreased the expression of the GCH-1 [43]. Since $\mathrm{BH}_{4}$ levels are directly linked to eNOS activity and endothelial function [44, 45] and GCH-1 is oxidatively degraded by activation of the proteasome26S [46], activation of antioxidant pathways by induction of HO-1 may represent an attractive explanation for the tolerance and endothelial dysfunction devoid profile 


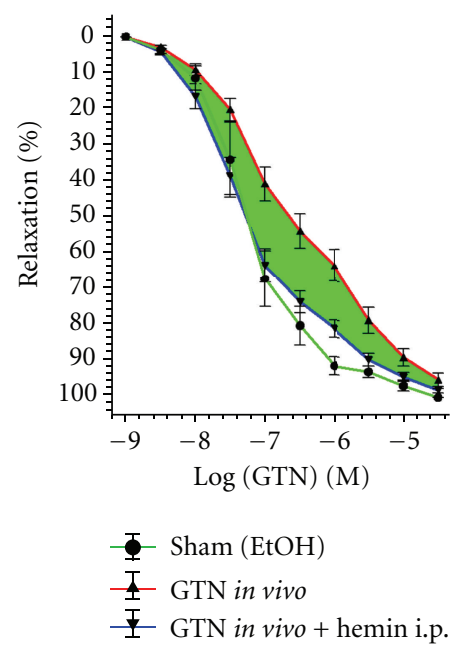

(a)

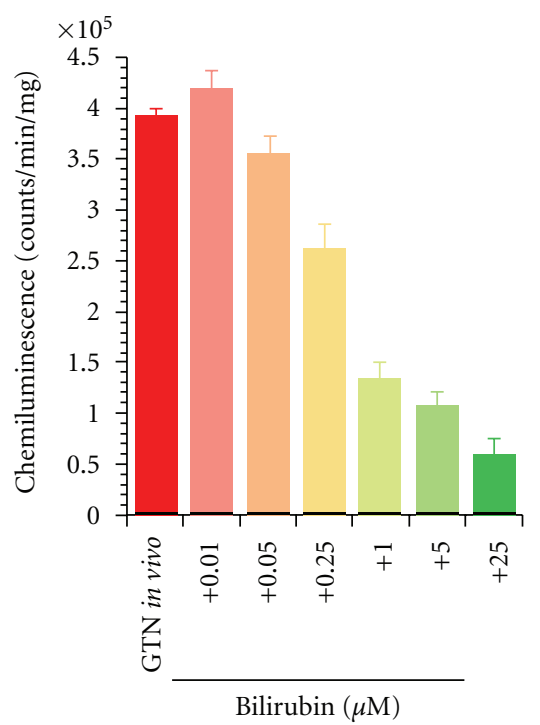

(d)
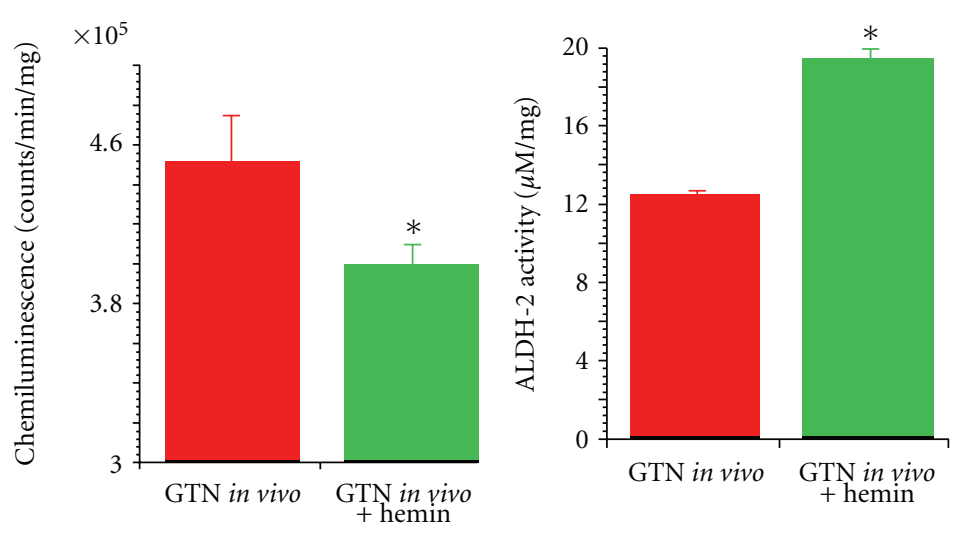

(b)

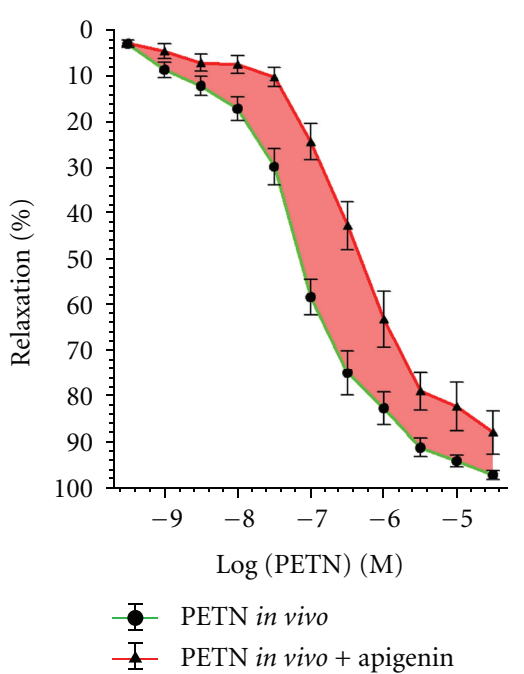

(e) (c)

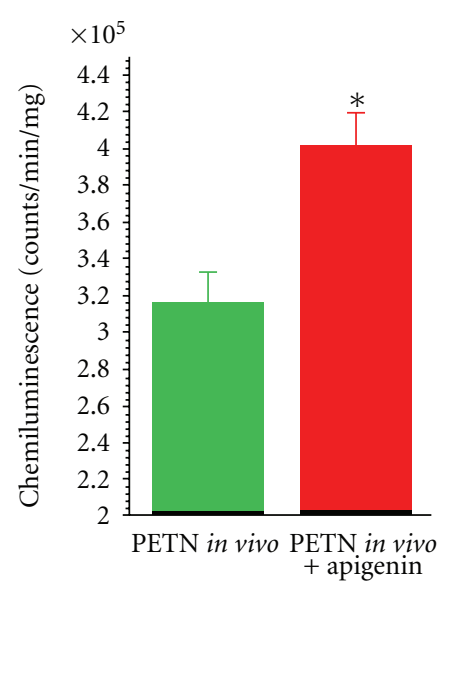

(f)

FIGURE 1: Effects of the HO-1 inducer hemin on GTN-induced tolerance and effects of the HO-1 suppressor apigenin on PETN side effects. Hemin $(25 \mathrm{mg} / \mathrm{kg})$ was administrated by single i.p. injection on day 3 of GTN treatment $(6.6 \mu \mathrm{g} / \mathrm{kg} / \mathrm{min}$ for 4 days via s.c. infusion) and markedly improved vascular GTN responsiveness (see area between curves) as demonstrated by isometric tension studies (a), a significant decrease in mitochondrial ROS formation (b), and improvement of mitochondrial ALDH-2 activity (c). Effects of bolus bilirubin on ROS formation in isolated heart mitochondria from GTN in vivo treated rats were determined by L- $012(100 \mu \mathrm{M}) \mathrm{ECL}$ in the presence of $2.5 \mathrm{mM}$ succinate and bilirubin $(0-25 \mu \mathrm{M})(\mathrm{d})$. Apigenin $(10 \mathrm{mg} / \mathrm{kg} / \mathrm{d})$ was coinfused over $4 \mathrm{~d}$ together with PETN $(10.5 \mu \mathrm{g} / \mathrm{kg} / \mathrm{min}$ for $4 \mathrm{days}$ via s.c. infusion). Apigenin cotreatment decreased PETN vasodilator potency (see area between curves) and induced a tolerance-like right shift in the PETN concentration-relaxation-curve (E). This observation was accompanied by increased mitochondrial ROS formation (F). Data are mean \pm SEM of $n=8-12$ (a), 40 (b), 6-18 (c), 4-6 (d), 9-11 (e), and 28-43 (f) independent experiments. ${ }^{*} P<0.05$ versus GTN or PETN treatment. Modified from [31].

of chronic PETN therapy and the undesired side effects of most other organic nitrates (but most pronounced for GTN treatment). Similar observations were made for extracellular superoxide dismutase (ecSOD), a downstream target of HO-1 and its products [47], which is upregulated by PETN $[34,48]$ but not by isosorbide-5-mononitrate (ISMN). Moreover, it was recently reported that HO-1 plays a significant role in the maintenance of soluble guanylyl cyclase (sGC) in a reduced heme state providing another important function for HO-1 in the regulatory pathways of vascular tone [49]. This novel beneficial property of HO-1 could also significantly improve vascular dysfunction in the setting of nitrate tolerance. These observations underline the distinct properties of organic nitrates, and these drugs do not represent a class with homogeneous effects [50] but also challenge the traditional assumption that all organic nitrates release the same vasoactive species (nitric oxide) an assumption that was already challenged for GTN in 2003 [51] (and reviewed in $[1,5]$ ).

In addition, previous work has demonstrated that organic nitrates have distinct effects on the function and survival of circulating angiogenic cells (formally known as 
endothelial progenitor cells) $[52,53]$. These studies showed that isosorbide dinitrate in contrast to PETN impair the migration and incorporation activities of these circulating angiogenic cells in an experimental model of myocardial infarction, whereas GTN in vitro exposure increased apoptosis while decreasing phenotypic differentiation, migration, and mitochondrial dehydrogenase activity in these cells. In a subsequent study, Lin et al. investigated the involvement of heme oxygenase- 1 for the related neovascularization process by hematopoietic stem cells and endothelial progenitor cells in the infarcted area [54]. Thum et al. have shown that the impaired function of these circulating angiogenic cells is based on oxidative stress as envisaged in the setting of diabetes, leading to eNOS uncoupling, which was improved by antioxidants (e.g., superoxide dismutase) [55]. These findings underline the importance of maintaining the $\mathrm{BH}_{4}$ levels to prevent eNOS uncoupling and the role of HO-1 for this antioxidant mechanism via increase in GCH-1 expression by carbon monoxide and bilirubin as outlined above. This concept is further supported by protective effects of folic acid (a precursor of $\mathrm{BH}_{4}$ ) on impaired endothelial function in GTN-treated healthy volunteers [56], and decreased $\mathrm{BH}_{4}$ levels in GTN-treated rabbits were restored by cotherapy with pioglitazone [57]. It should be noted that another group found no association between aortic $\mathrm{BH}_{4}$ content and eNOS function in response to GTN ex vivo and in vivo treatment [58].

Finally, it should be mentioned that oxidative stress in response to organic nitrates may also be protective by a process called ischemic preconditioning (IPC) [5961]. Recently, the involvement of HO-1 in organic nitratemediated IPC was proposed $[59,62]$ as an explanation for the sustained IPC protective effect under chronic PETN therapy but loss of this beneficial effect under chronic GTN therapy. This is in accordance with the accepted view that HO-1 plays a role in IPC $[63,64]$.

\section{Molecular Proof of a Role of HO-1 for the Tolerance-Devoid Profile of PETN by Using HO- $\mathrm{I}^{+/-}$Mice}

The role of HO-1 as the antioxidative principle of PETN was elucidated by 3-key experiments aiming to prove this hypothesis at a molecular basis [32]. The first experimental setup consisted of the treatment of control $\left(\mathrm{HO}-1^{+/+}\right)$ and partially deficient $\left(\mathrm{HO}-1^{+/-}\right)$mice with PETN. In $\mathrm{HO}-1^{+/-}$but not $\mathrm{HO}-1^{+/+}$mice, PETN infusion induced desensitization to PETN-induced vasorelaxation (envisaged by impaired vasodilator potency of the drug in isolated aortic segments) and increased mitochondrial ROS formation (Figures 2(a) and 2(b)), demonstrating nitrate tolerance to PETN in a setting of HO-1 deficiency. The second approach was on the basis of HO-1 induction by the known inducer of this enzyme, hemin, which improved angiotensin-II-(highdose) dependent endothelial dysfunction and prevented activation of NADPH oxidase in $\mathrm{HO}-1^{+/+}$mice (Figures 2(c) and 2(d)). The third experiment demonstrated that PETN did not improve endothelial dysfunction and cardiac oxidative stress in angiotensin-II-(low-dose) treated HO$1^{+/-}$mice but further impaired vascular function and increased ROS formation in this setting (Figure 2(e) and $2(\mathrm{f}))$. It is somewhat surprising that already heterozygous deficiency in HO-1 leads to complete loss of the beneficial and protective effects of PETN but may also underline how essential the upregulation of $\mathrm{HO}-1$ is to prevent nitrate tolerance, endothelial dysfunction, and oxidative stress under chronic therapy with organic nitrates. It would be of great clinical importance to study the vasodilatory potency of GTN and development of nitrate tolerance under chronic GTN therapy in human individuals with Morbus Meulengracht (Gilbert's syndrome) to translate our preclinical data from bench to bedside and to further explore the therapeutical potential of HO-1 induction to overcome the side effects of GTN therapy. Since human subjects with hyperbilirubinemia (e.g., new born with mild jaundice or patients with Gilbert's syndrome) have a better prognosis and have a significant lower cardiovascular risk [65], it may be hypothesized that they will also display a lower degree of nitrate tolerance in response to chronic GTN therapy.

The beneficial effects of HO-1 induction on mitochondrial RONS formation may be attributed to the presence of HO-1 in mitochondria [66] and the improvement of mitochondrial biogenesis as well as suppression of doxorubicin cardiotoxicity [67]. Recent report also suggests that targeting HO-1 to mitochondria can prevent inflammationtriggered mitochondrial oxidative stress and apoptosis [68]. Since the side effects of chronic GTN therapy are mainly based on adverse regulation of mitochondrial function such as the inhibition of mitochondrial aldehyde dehydrogenase (ALDH-2) [23], increase in mitochondrial oxidative stress $[23,27]$, increase in cellular apoptosis [53], the induction of a mitochondrial antioxidant principle (HO-1) would be most effective to prevent GTN-induced tolerance and endothelial dysfunction. This concept was supported by previous reports on the improvement of GTN side effects by a mitochondriatargeted antioxidant (mitoQ) [30], by aggravation of GTN toxicity by partial deficiency in the mitochondrial superoxide dismutase (Mn-SOD) [28], and by interference of blockers of the mitochondrial pores (cyclosporine A and glibenclamide) with the crosstalk between cytosolic and mitochondrial sources of RONS [69]. Vice versa, induction of HO-1 may explain the beneficial profile of PETN [70]. This concept is summarized in Figure 3 and was previously published [31]. To describe the content of this scheme briefly: In vivo treatment with PETN is devoid of tolerance and endothelial dysfunction induction in response to chronic in vivo treatment. In contrast to GTN, PETN does not increase vascular oxidative stress and therefore does not interfere with its bioactivation by ALDH-2. A likely explanation for this beneficial property of PETN is the induction of the antioxidant enzyme HO- 1 and subsequent increases in the expression of ferritin as well as other protective downstream mechanisms not shown here (e.g., ecSOD, GCH-1, and sGC) in vascular tissue but also in the heart. This favorable characteristics of PETN may also explain why therapy with GTN but not PETN causes tolerance and stimulates ROS production in human subjects $[9,71]$. 

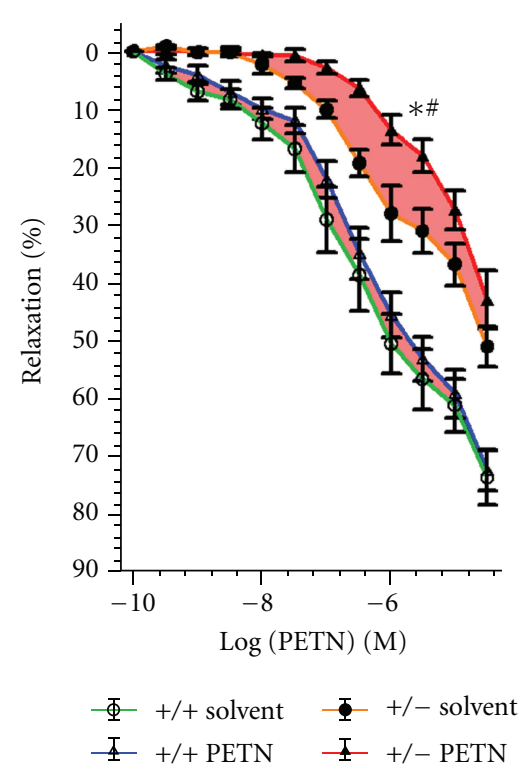

(a)

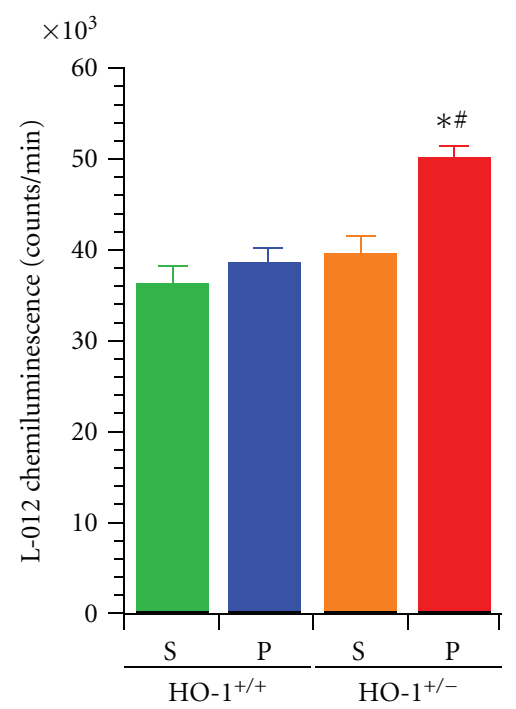

(b)
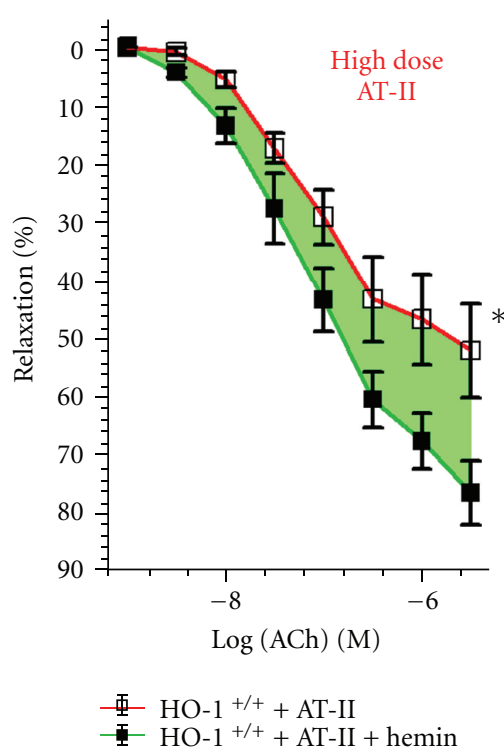

(c)

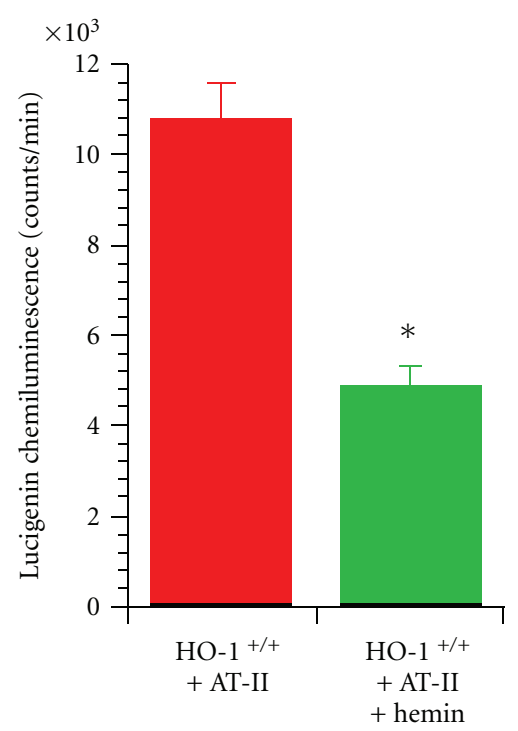

(d)

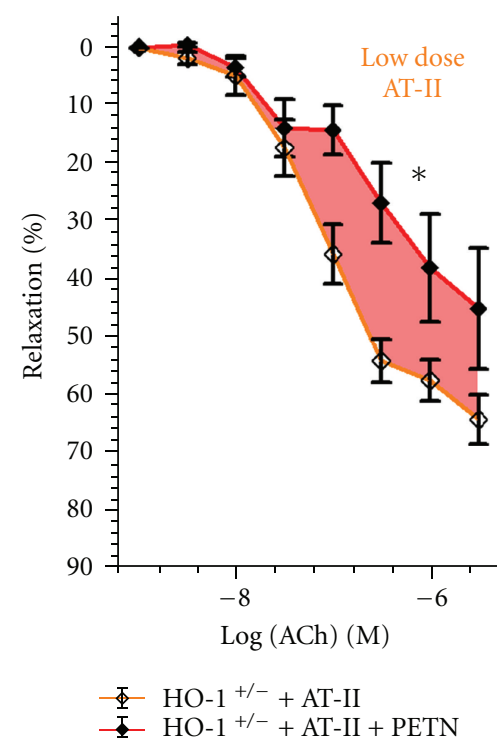

(e)

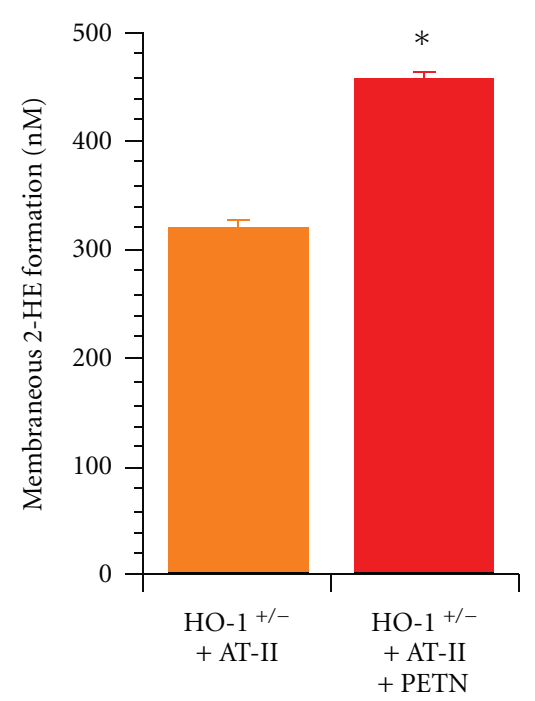

(f)

FIGURE 2: Effects of HO-1 deficiency versus HO-1 induction on vascular improvement by pentaerithrityl tetranitrate (PETN). (a, b) PETN treatment $(75 \mathrm{mg} / \mathrm{kg} / \mathrm{d}$ for $4 \mathrm{~d})$ had no effect on PETN potency (PETN-induced relaxation) in aorta from control mice $\left(\mathrm{HO}-1^{+/+}\right)$but caused nitrate tolerance (see area between curves) in aorta from mice with partial HO-1 deficiency $\left(\mathrm{HO}-1^{+/-}\right.$). In accordance, cardiac mitochondrial ROS formation (L-012 ECL) was increased in PETN-treated HO- $1^{+/-}$mice. $P<0.05: *$ versus HO- $1^{+/+} / \mathrm{DMSO}$; ${ }^{*}$ ersus HO- $1^{+/-} / \mathrm{DMSO}$. S: solvent; P: PETN-treated. (c, d) Hemin (25 mg/kg i.p.)-triggered HO-1 induction improved high-dose AT-II (1 mg/kg/d for 7d)-induced endothelial dysfunction (ACh-response) in aorta (see area between curves) and NADPH oxidase activity in heart (lucigenin ECL) from control mice $\left(\mathrm{HO}-1^{+/+}\right) . P<0.05:{ }^{*}$ versus AT-II-treated HO- $1^{+/+} / \mathrm{DMSO}$. (e, f) PETN $(75 \mathrm{mg} / \mathrm{kg} / \mathrm{d}$ for $7 \mathrm{~d})$ failed to prevent endothelial dysfunction (ACh-response) induced by low-dose AT-II $(0.1 \mathrm{mg} / \mathrm{kg} / \mathrm{d}$ for $7 \mathrm{~d})$ in aorta from HO- ${ }^{+/-}$mice (see area between curves). In accordance, PETN did not improve NADPH oxidase activity (2-HE formation by HPLC analysis) in cardiac samples from AT-II-treated HO$1^{+/-}$mice. $P<0.05: *$ versus AT-II-treated HO- $1^{+/-} /$DMSO. All data are mean \pm SEM of aortic rings and hearts from 4-5 animals/group. Modified from [32].

\section{Effects of Organic Nitrates on Gene Expression}

There are several examples in the literature showing a transcriptional as well as posttranscriptional modulation of gene expression by nitric oxide (NO) [72-75]. The activity of several transcription factors like NF- $\kappa \mathrm{B}, \mathrm{AP} 1$ [74], or NRF2 [76] as well as RNA-binding protein like HuR [77] has been shown to be modulated by NO (directly or indirectly via cGMP). Organic nitrates are believed to be indirect 


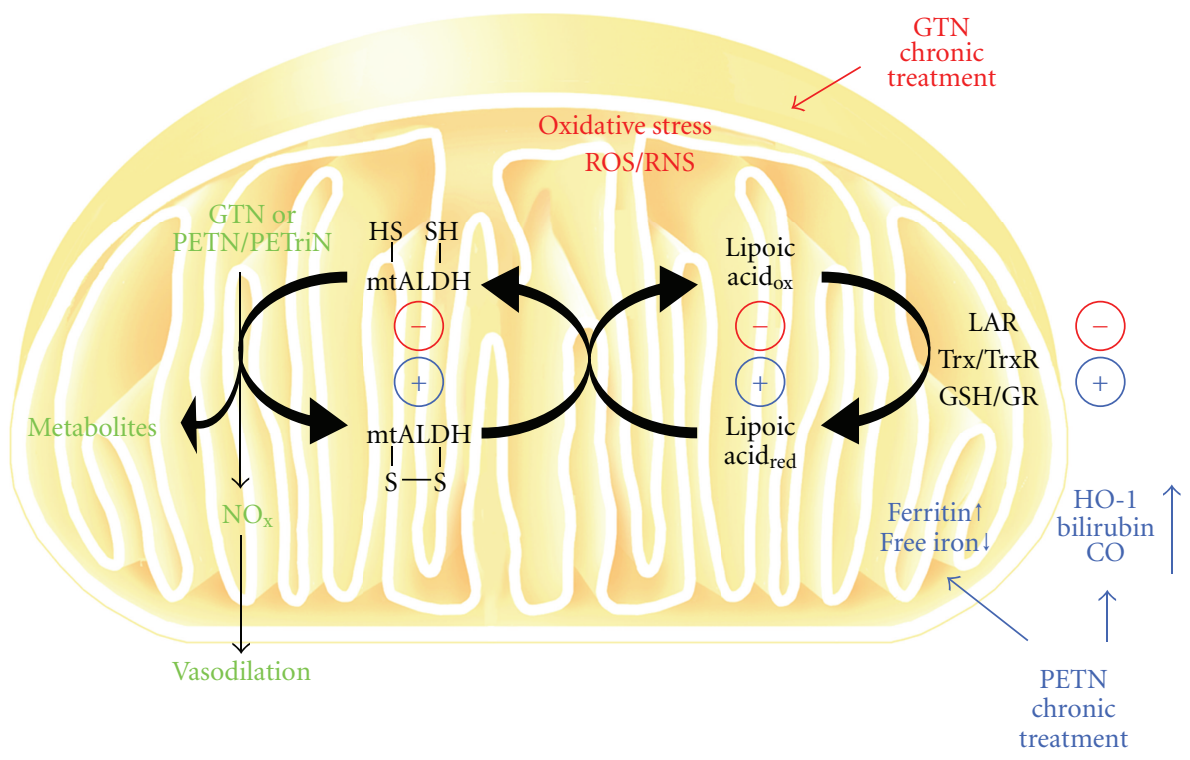

FIGURE 3: Scheme illustrating the mechanisms underlying the oxidative stress concept of nitrate tolerance in response to GTN treatment and the mechanisms underlying the beneficial vascular effects in response to PETN. PETN and GTN are bioactivated by mitochondrial ALDH (ALDH-2) yielding 1,2-glyceryl dinitrate and PETriN, respectively, as well as a yet undefined nitrogen species $\left(\mathrm{NO}_{x}\right.$, probably nitrite) that undergoes further reduction by the mitochondrial respiratory chain or acidic disproportionation to form an activator of sGC (probably nitrico xide). GTN treatment induces mitochondrial reactive oxygen and nitrogen species formation (ROS/RNS). These ROS/RNS in turn inhibit the GTN bioactivation process by inactivation of ALDH-2 or by inhibiting the repair system of the ALDH-2, which includes lipoic acid, as well as a reductase system depending on the NADH or NADPH (lipoicacid reductase (LAR), thioredoxin/thioredoxin reductase (Trx/TrxR) or glutathione/glutathione reductase (GSH/GR). In contrast to GTN, PETN provides potent antioxidative effects by inducing HO-1 and ferritin, which in turn decrease ROS levels and therefore protect the ALDH-2 from ROS mediated inactivation. Adapted from [31].

NO-donors. Therefore, it seems very likely that treatment with organic nitrates may have implications on the expression of multiple genes. GTN has been described to enhance the expression of c-fos, COX-2, Bcl2, and nNOS in brain nuclei [78-81], to reduce beta-catenin expression in colon cancer cells [82], and to reduce NOX1, NOX2, NOX4 and ALDH2-expression in rat aorta and rat smooth muscle cells [83]. Using microarray analysis, Wang et al. described changes of the expression of 290 genes in the aortas of rats treated with GTN for $8 \mathrm{~h}$ [84]. Analyzing the gene expression in the hearts treated for 4 days with GTN, the authors described expressional changes of more than 500 genes [85].

There are also some reports about the expressional effects of PETN [29, 31, 35, 36, 62]. PETN (but not GTN) has been shown to enhance the expression of the antioxidant genes HO- 1 and ferritin heavy chain $(\mathrm{FeHc})$ in human endothelial cells $[29,35,36,62]$ and rat aorta [31]. In microarray experiments, the authors showed that PETN modulated the expression of more than 1200 genes in the hearts of rats treated with PETN for 4 days [85].

\section{Molecular Mechanisms Involved in the Regu- lation of Gene Expression by Organic Nitrates}

The comparison of the $5^{\prime}$-flanking sequences of the HO-1 gene (promoter, $10 \mathrm{~kb}$ ) in different species (rat, mouse, rhesus macaque, chimpanzee, and human) displays regions with very high homology between these species ("evolutionary conserved regions," ECRs; see Figure 4). These ECR are likely to be involved in the regulation of the HO-1 promoter activity. Bioinformatic analyses show that these ECR contain the binding sites of transcription factors (e.g., NRF2) known to regulate HO-1 promoter activity in different mammalian cell systems (e.g., macrophages, fibroblasts, smooth muscle cells [33]) after various stimuli. In human SH-SY5Y neuroblastoma [86] or rat vascular smooth muscle cells [87], the enhancement of the HO-1 expression by different NO donors DETA-NO has been shown to depend on the expression of NRF2.

To analyze the molecular mechanisms of the regulation of the HO-1 expression by organic nitrates, the authors cloned a $11 \mathrm{~kb}$ fragment of the human HO-1 promoter into a luciferase reporter gene construct. This construct was stably transfected into human epithelial DLD-1 cells (DLD1-HO$11 \mathrm{~kb}-$ Prom). These cells were treated for $8 \mathrm{~h}$ with PETN, ISDN, ISMN, or GTN (or the respective solvents, dimethyl sulfoxide DMSO, $\mathrm{H}_{2} \mathrm{O}$, ethanol EtOH). Cell extracts were prepared, and luciferase activity was measured. As shown in Figure 5, only PETN was able to enhance the promoter activity of the human HO-1 gene. Therefore, the enhancement of HO-1 expression by PETN seems to depend at least partly on PETN-induced enhancement of the HO-1 promoter. A similar comparison of the effects of different organic nitrates on HO-1 induction was recently published [34].

To analyze the involvement of the transcription factor NRF2 in this PETN-mediated enhancement of HO-1 


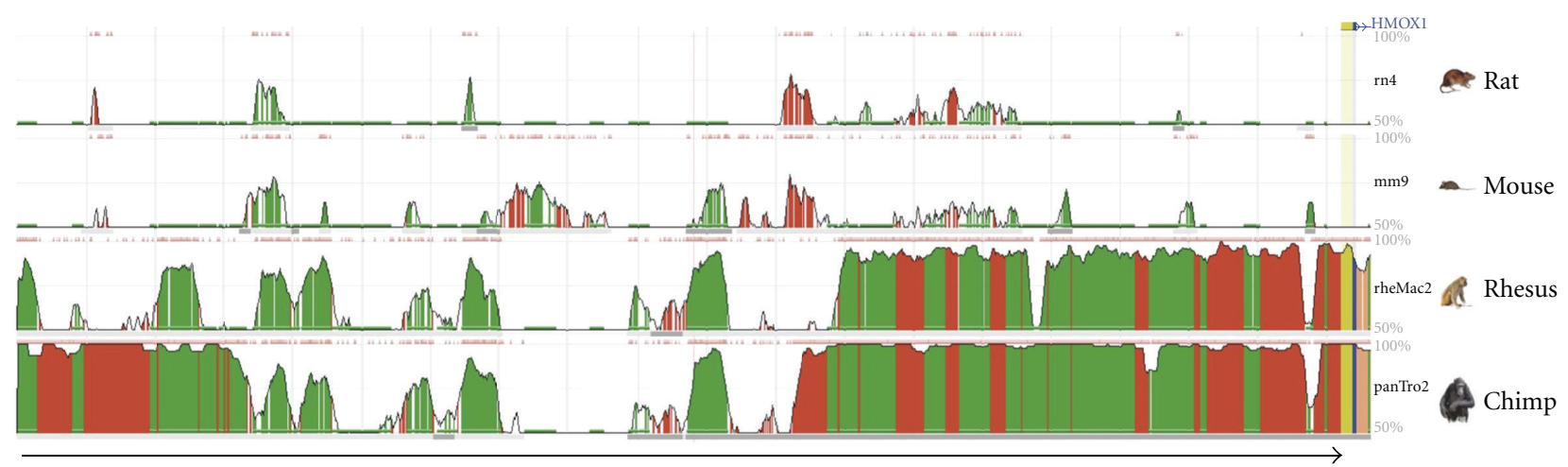

(a)

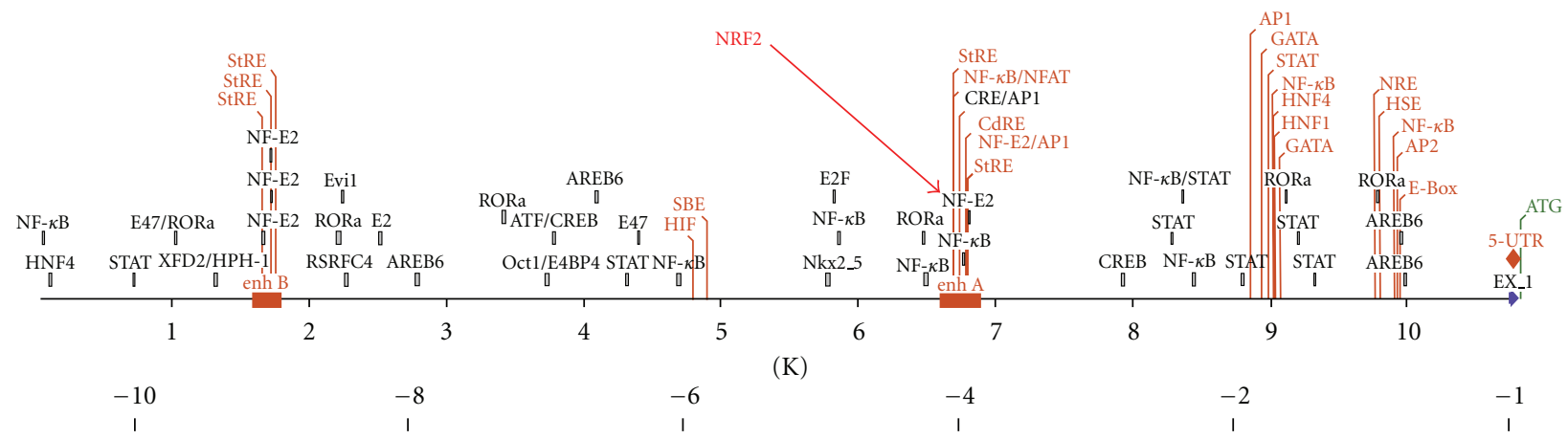

$(\mathrm{kb})$

(b)

FIgURE 4: Comparison of the HO-1 promoter sequences of different species. (a) Comparison of the $5^{\prime}$-flanking sequences ( $10 \mathrm{~kb}$ ) of the rat, mouse, rhesus macaque, chimpanzee, and human (arrow) HO-1 gene using the ECR-Browser software (http://ecrbrowser.dcode.org/). The search area was $10 \mathrm{bp}$, and the minimal homology was $80 \%$. The height of the curves $(50 \%<X<100 \%)$ indicates the homology (red: intergenic regions, green: single repeats, yellow: untranslated regions of the RNA (UTR), blue: exon, salmon: intron, pink ECR, above). (b) Map of transcription factor binding sites (TFBS) in the human HO-1 promoter. TFBS labeled in red have been verified experimentally in different cells systems (see also [33]).

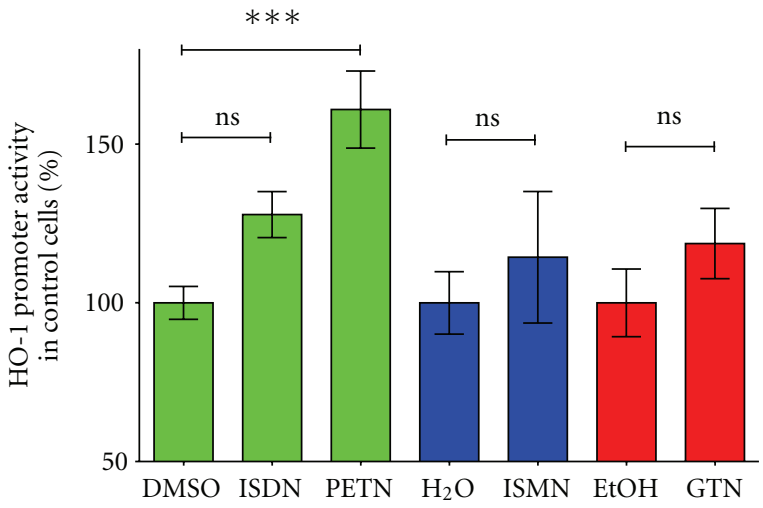

FIGURE 5: Effects of organic nitrates on the human HO-1 promoter activity. DLD1-HO-11kb-Prom cells were treated for $8 \mathrm{~h}$ with isosorbide dinitrate ISDN, PETN, isosorbide-5-mononitrate ISMN, or GTN at a concentration of $50 \mu \mathrm{M}$ or the respective solvent $\left(\mathrm{DMSO}, \mathrm{H}_{2} \mathrm{O}, \mathrm{EtOH}\right)$. Extracts were prepared, and luciferase activity and protein content were measured, and luciferase activity was normalized to the protein content. Shown (mean \pm SEM; $n=8-10$ ) are the normalized luciferase activity values. The normalized luciferase activity of the cell treated with solvent was set to $100 \%$. ( ${ }^{* * *}=P<0.001$, ns: not significant different from solvent-treated cells.) These data were partly published in [34]. 
promoter activity, NRF2-knockdown experiments using a specific anti-NRF2 siRNA were performed. These experiments clearly showed that the PETN-mediated enhancement of the human HO-1 promoter activity depends on the NRF2 expression (see Figure 6) [34]. Therefore, it is likely to speculate that the NO generated by PETN activates NRF2 which in turn binds to the HO-1 promoter and enhances transcription.

Beside transcriptional regulation, the modulation of expression of HO-1 has been shown to depend on posttranscriptional mechanisms [77, 88-92]. Posttranscriptional regulation of mRNA stability and translatability mostly depends on sequences found in the $3^{\prime}$ - untranslated sequence (3'-UTR) of the mRNAs [93, 94]. Analysis of the $3^{\prime}$ UTR sequences of the HO-1 mRNA of different species (rat, mouse, rhesus macaque, chimpanzee, and human, see Figure 7) reveals evolutionary conserved regions (ECR). In the 3'-UTR sequences of all species, AU-rich elements (AREs) is highly conserved. AREs have been shown to be the binding sites of RNA, binding proteins like HuR or KSRP, which stabilize or destabilize the mRNAs. In a recent paper, the NO-dependent stabilization of the HO-1 mRNA in murine fibroblasts was shown to depend on the RNAbinding protein $\mathrm{HuR}$ [77].

To analyze the effects of organic nitrates on the HO-1 mRNA stability, the authors cloned the $3^{\prime}$-UTR sequence of the human HO-1 mRNA behind the luciferase reporter gene (pGL3-Control-HO-1-3-UTR). Stable human endothelial cells (EA.hy 926) were transiently transfected with this construct and treated with GTN or PETN (see Figure 8). PETN but not GTN enhanced luciferase activity in the transfected cells indicating a PETN-dependent stabilization of the HO-1 mRNA (unpublished data, Hartmut Kleinert).

\section{Conclusions and Clinical Implications}

Organic nitrates like GTN or PETN seem to have marked distinct pharmacological properties and side effects [50], translating to different therapeutic profiles and clinical properties (e.g., induction or lack of nitrate tolerance) [9], which may be at least in part explained by their different effects on HO-1 gene expression [2]. This may be attributed to the different amounts of bioactive NO generated from these compounds. As GTN markedly enhances ROS production in cells, only small amounts of bioactive NO are produced. In contrast, PETN incubation results in decent amount of bioactive NO (or a related species such as S-nitrosothiols or heme-NO) resulting in enhanced NRF2 binding to the HO-1 promoter and HuR binding to the HO-1 mRNA. Thereby, PETN enhances HO- 1 expression both by transcriptional and posttranscriptional effects (see Figure 9). Since HO-1 and its products may directly regulate other genes [47], distinct modulation of HO-1 expression by different organic nitrates may also explain differential regulation of gene expression by organic nitrates in general (e.g., GTN versus PETN) [85].

First clinical evidence for the importance of HO-1 to overcome nitrate tolerance is based on the observation that statin therapy (well-known inducers of $\mathrm{HO}-1$ ) was able to

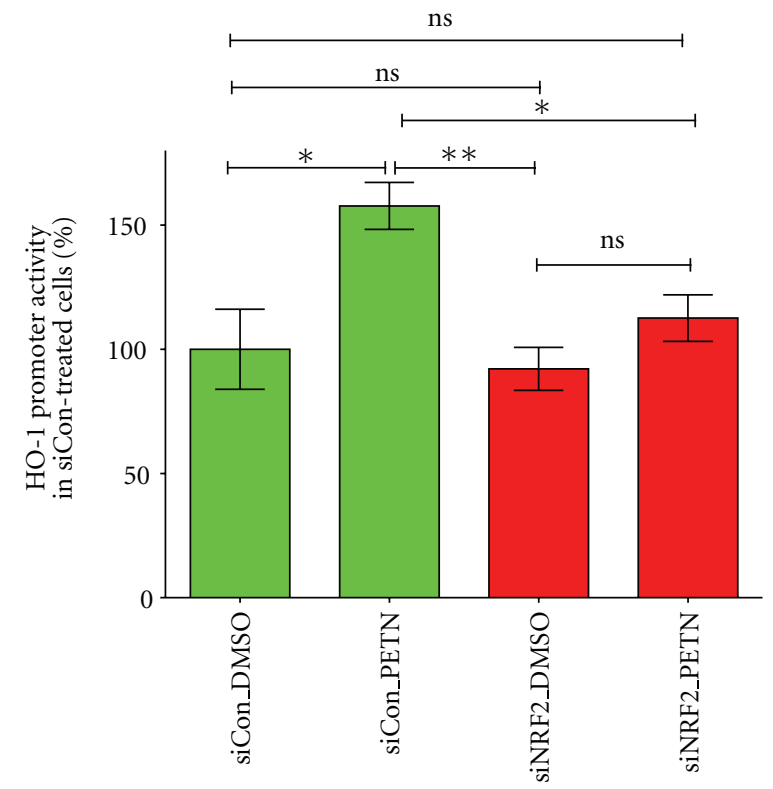

FIgure 6: PETN-induced enhancement of the human HO-1 promoter activity depends on NRF2. DLD1-HO-11kb-Prom cells were transfected with a specific anti-NRF2 siRNA (siNRF2) or a nonrelated control siRNA (siCon). After $48 \mathrm{~h}$, the cells were incubated with PETN or the solvent DMSO. Extracts were prepared and luciferase activity and protein content were measured, and luciferase activity was normalized to the protein content. Shown (mean \pm SEM; $n=5-6$ ) are the normalized luciferase activity values. The normalized luciferase activity of the cell treated with solvent and siCon was set to $100 \%$. $\left({ }^{* *}=P<0.01,{ }^{*}=P<\right.$ 0.05 , ns: not significant different to DMSO and siCon-treated cells. Modified from [34].

prevent nitrate tolerance in human subjects [40, 41]. Despite the fact that published preclinical data clearly show that an organic nitrate with $\mathrm{HO}-1$ inducing properties such as PETN has less side effects [31] and even has beneficial effects on experimental hypertension [32], diabetes [34], and atherosclerosis [95], these findings still lack molecular proof in human subjects to increase the clinical importance of this concept. A proof of concept study aiming to demonstrate that individuals with Morbus Meulengracht (Gilbert's syndrome), displaying increased HO-1 activity and bilirubin levels, are devoid of tolerance, endothelial dysfunction and oxidative stress in response to nitroglycerin (GTN) therapy could provide a new therapeutic option to overcome these undesired side effects of GTN treatment.

\section{Authors' Contribution}

A. Daiber and H. Kleinert wrote the first draft, prepared the figures, and designed the original research. M. Oelze, P. Wenzel, F. Bollmann, and A. Pautz commented on subsequent drafts and have performed the original experiments. All authors have approved the paper.

\section{Acknowledgments}

The technical assistance of Jörg Schreiner and Angelica Karpi during the authors ongoing studies during the last years 


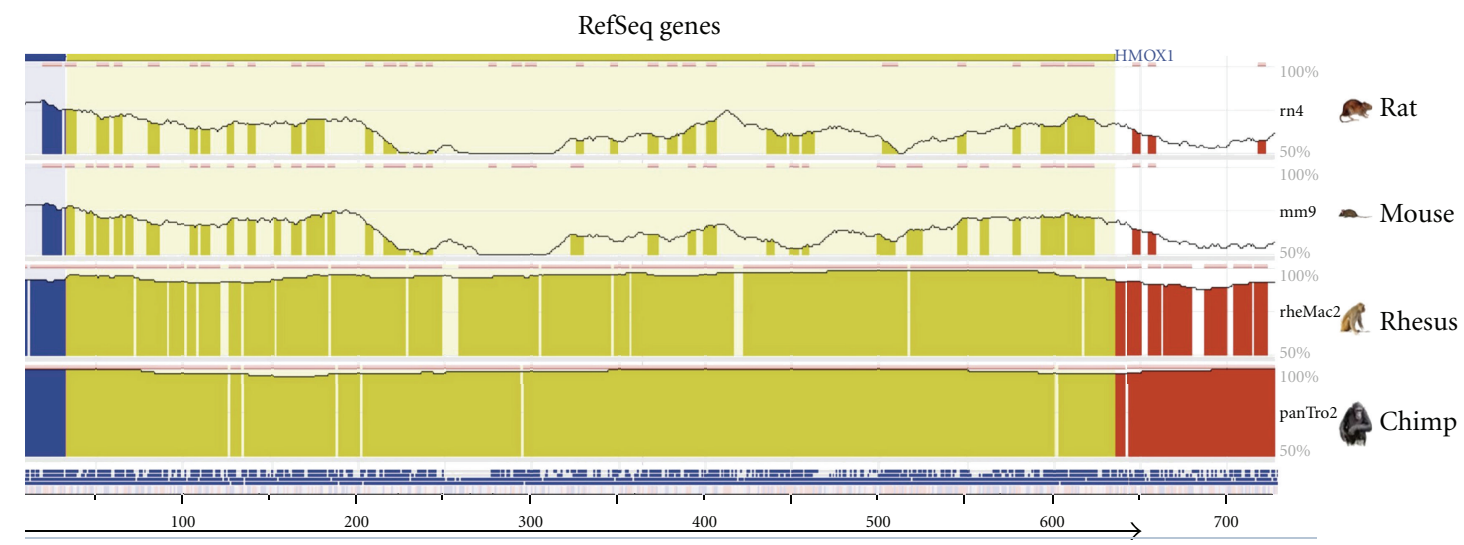

(a)

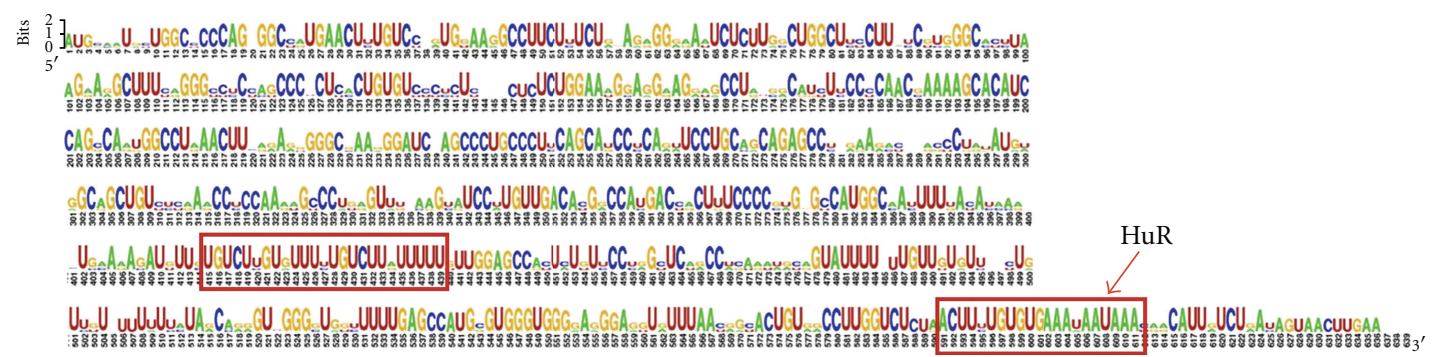

(b)

Figure 7: Comparison of the $3^{\prime}$-UTR of the HO-1 mRNA of different species. (a) The $3^{\prime}$-UTR sequences of the HO-1 mRNA from rat, mouse, rhesus macaque, chimpanzee and human was compared using the ECR-Browser software. The search area was 10 $\mathrm{bp}$ and the minimal homology was $80 \%$. The height of the curves $(50 \%<X<100 \%)$ indicates the homology (red $=$ intergenic regions, yellow $=$ untranslated regions of the RNA (UTR), blue = exon, pink ECR, above). (b) Using the software RNALogo (http://rnalogo.mbc.nctu.edu.tw/createlogo.html) a consensus sequence of all $53^{\prime}$-UTR sequences was generated. The height of the letters indicate the frequency of the appearance of this base. AREs are marked by a red box. A putative HuR binding site is indicated.

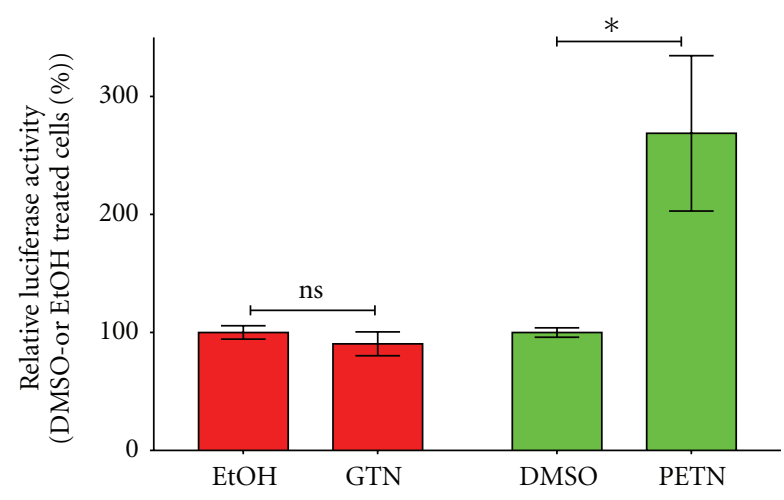

FIgURE 8: Post-transcriptional regulation of the human HO-1 expression. Human endothelial EA.hy 926 cells were transiently transfected with pGL3-Control-HO-1-3-UTR and pRenilla (normalization of transfection efficiency). After $24 \mathrm{~h}$ the cells were treated with $50 \mu \mathrm{M}$ nitroglycerin (GTN) or PETN (or the solvents ethanol [EtOH] or DMSO) for 6h. Extracts were prepared and luciferase and Renilla activity were determined. The luciferase activity was normalized to the renilla activity. Shown (mean \pm SEM; $n=6-8$ ) are the normalized luciferase activity values. The normalized luciferase activity of the cell treated with solvent were set to $100 \%\left({ }^{*}=P<0.05\right.$; ns $=$ not significant versus EtOH- or. DMSO treated cells). 


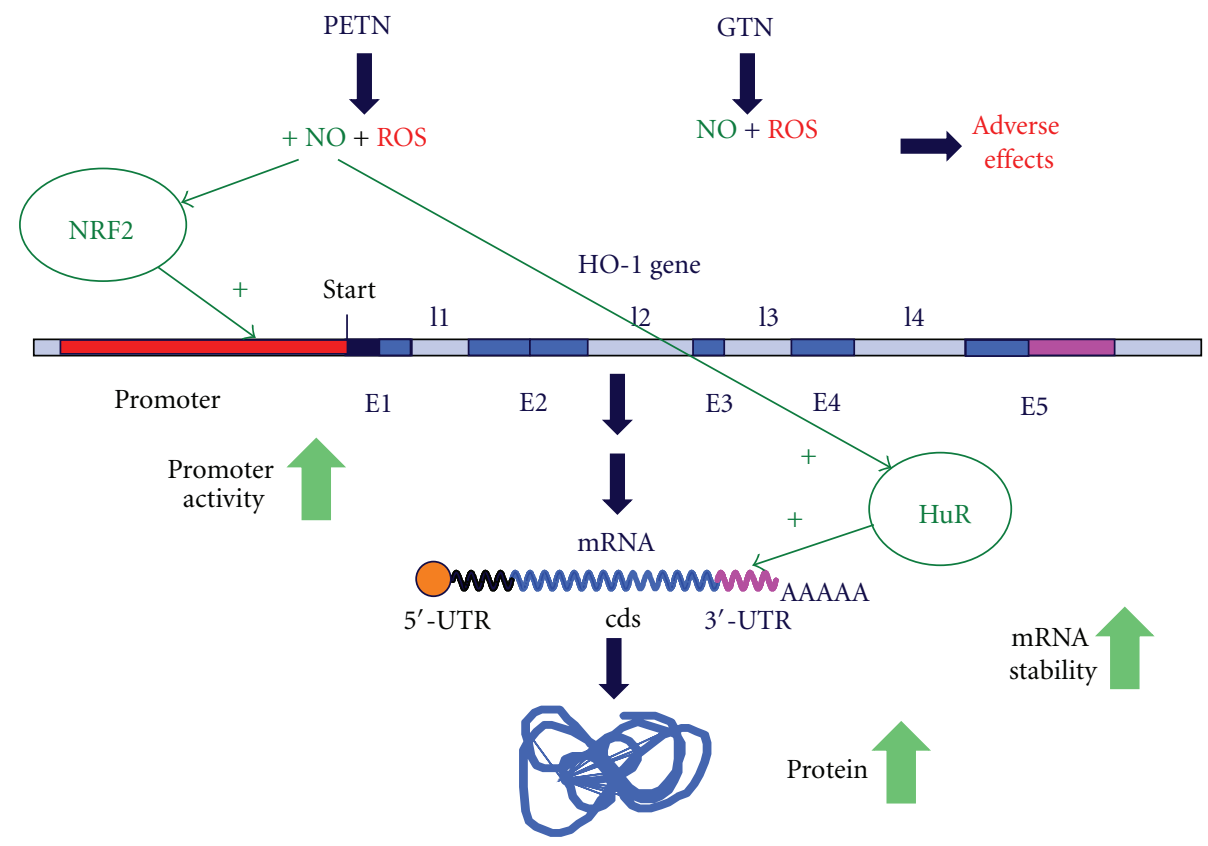

FIGURE 9: Molecular mechanisms of PETN-mediated enhancement of HO-1 expression. The high amounts of bioactive NO generated from PETN (but not GTN) activate the transcription factor NRF2 and thereby enhance the HO-1 promoter activity. In addition, the interaction of the stabilizing RNA binding protein HuR with the $3^{\prime}$-UTR of the HO-1 mRNA is enhanced. Both effects result in an enhancement of HO-1 expression (E: exon, I: intron).

is gratefully acknowledged. They thank Margot Neuser for graphical assistance. The present work was supported by generous financial support by the Johannes Gutenberg University and Medical Center Mainz (MAIFOR and Forschungsfonds grants) and by Actavis Deutschland $\mathrm{GmbH}$ to A. Daiber and H. Kleinert. A. Daiber and H. Kleinert received research grants and honoraries from Actavis Deutschland $\mathrm{GmbH}$ (manufacturer and German distributor of PETN). The ethical approval for this work is not suitable.

\section{References}

[1] T. Munzel, A. Daiber, and A. Mulsch, "Explaining the phenomenon of nitrate tolerance," Circulation Research, vol. 97, no. 7, pp. 618-628, 2005.

[2] T. Munzel, A. Daiber, and T. Gori, "Nitrate therapy: new aspects concerning molecular action and tolerance," Circulation, vol. 123, no. 19, pp. 2132-2144, 2011.

[3] A. Daiber, T. Munzel, and T. Gori, "Organic nitrates and nitrate tolerance-state of the art and future developments," Advances in Pharmacology, vol. 60, pp. 177-227, 2010.

[4] A. Daiber, M. Oelze, P. Wenzel et al., "Nitrate tolerance as a model of vascular dysfunction: roles for mitochondrial aldehyde dehydrogenase and mitochondrial oxidative stress," Pharmacological Reports, vol. 61, no. 1, pp. 33-48, 2009.

[5] A. Daiber, P. Wenzel, M. Oelze, and T. Munzel, "New insights into bioactivation of organic nitrates, nitrate tolerance and cross-tolerance," Clinical Research in Cardiology, vol. 97, no. 1, pp. 12-20, 2008.

[6] K. K. Griendling and G. A. FitzGerald, "Oxidative stress and cardiovascular injury: part II: animal and human studies," Circulation, vol. 108, no. 17, pp. 2034-2040, 2003.
[7] A. Daiber and T. Münzel, Oxidativer Stress, Redoxregulation und NO-Bioverfügbarkeit-Experimentelle und Klinische Aspekte, Steinkopff Verlag Darmstadt, Darmstadt, Germany, 2006.

[8] E. Schulz, N. Tsilimingas, R. Rinze et al., "Functional and biochemical analysis of endothelial (Dys)function and $\mathrm{NO} / \mathrm{cGMP}$ signaling in human blood vessels with and without nitroglycerin pretreatment," Circulation, vol. 105, no. 10, pp. 1170-1175, 2002.

[9] T. Gori, A. Al-Hesayen, C. Jolliffe, and J. D. Parker, "Comparison of the effects of pentaerythritol tetranitrate and nitroglycerin on endothelium-dependent vasorelaxation in male volunteers," American Journal of Cardiology, vol. 91, no. 11, pp. 1392-1394, 2003.

[10] M. Sekiya, M. Sato, J. Funada, T. Ohtani, H. Akutsu, and K. Watanabe, "Effects of the long-term administration of nicorandil on vascular endothelial function and the progression of arteriosclerosis," Journal of Cardiovascular Pharmacology, vol. 46, no. 1, pp. 63-67, 2005.

[11] G. R. Thomas, J. M. DiFabio, T. Gori, and J. D. Parker, "Once daily therapy with isosorbide-5-mononitrate causes endothelial dysfunction in humans. Evidence of a free-radicalmediated mechanism," Journal of the American College of Cardiology, vol. 49, no. 12, pp. 1289-1295, 2007.

[12] T. Munzel, H. Sayegh, B. A. Freeman, M. M. Tarpey, and D. G. Harrison, "Evidence for enhanced vascular superoxide anion production in nitrate tolerance. A novel mechanism underlying tolerance and cross-tolerance," Journal of Clinical Investigation, vol. 95, no. 1, pp. 187-194, 1995.

[13] T. Munzel, S. Kurz, S. Rajagopalan et al., "Hydralazine prevents nitroglycerin tolerance by inhibiting activation of a membrane-bound NADH oxidase: a new action for an old drug," Journal of Clinical Investigation, vol. 98, no. 6, pp. 14651470, 1996. 
[14] T. Munzel and D. G. Harrison, "Evidence for a role of oxygen derived free radicals and protein kinase $\mathrm{C}$ in nitrate tolerance," Journal of Molecular Medicine, vol. 75, no. 11-12, pp. 891-900, 1997.

[15] T. Munzel, A. Giaid, S. Kurz, D. J. Stewart, and D. G. Harrison, "Evidence for a role of endothelin 1 and protein kinase $\mathrm{C}$ in nitroglycerin tolerance," Proceedings of the National Academy of Sciences of the United States of America, vol. 92, no. 11, pp. 5244-5248, 1995.

[16] A. Warnholtz, H. Mollnau, T. Heitzer et al., "Adverse effects of nitroglycerin treatment on endothelial function, vascular nitrotyrosine levels and cGMP-dependent protein kinase activity in hyperlipidemic Watanabe rabbits," Journal of the American College of Cardiology, vol. 40, no. 7, pp. 1356-1363, 2002.

[17] U. Hink, M. Oelze, P. Kolb et al., "Role for peroxynitrite in the inhibition of prostacyclin synthase in nitrate tolerance," Journal of the American College of Cardiology, vol. 42, no. 10, pp. 1826-1834, 2003.

[18] A. Daiber, M. Oelze, M. Coldewey et al., "Hydralazine is a powerful inhibitor of peroxynitrite formation as a possible explanation for its beneficial effects on prognosis in patients with congestive heart failure," Biochemical and Biophysical Research Communications, vol. 338, no. 4, pp. 1865-1874, 2005.

[19] P. Wenzel, U. Hink, M. Oelze et al., "Role of reduced lipoic acid in the redox regulation of mitochondrial aldehyde dehydrogenase (ALDH-2) activity: implications for mitochondrial oxidative stress and nitrate tolerance," Journal of Biological Chemistry, vol. 282, no. 1, pp. 792-799, 2007.

[20] Q. Fan, F. Gao, L. Zhang, T. A. Christopher, B. L. Lopez, and X. L. Ma, "Nitrate tolerance aggravates postischemic myocardial apoptosis and impairs cardiac functional recovery after ischemia," Apoptosis, vol. 10, no. 6, pp. 1235-1242, 2005.

[21] G. Abou-Mohamed, J. A. Johnson, L. Jin et al., "Roles of superoxide, peroxynitrite, and protein kinase $\mathrm{C}$ in the development of tolerance to nitroglycerin," Journal of Pharmacology and Experimental Therapeutics, vol. 308, no. 1, pp. 289-299, 2004.

[22] M. J. Mihm, C. M. Coyle, L. Jing, and J. A. Bauer, "Vascular peroxynitrite formation during organic nitrate tolerance," Journal of Pharmacology and Experimental Therapeutics, vol. 291, no. 1, pp. 194-198, 1999.

[23] K. Sydow, A. Daiber, M. Oelze et al., "Central role of mitochondrial aldehyde dehydrogenase and reactive oxygen species in nitroglycerin tolerance and cross-tolerance," Journal of Clinical Investigation, vol. 113, no. 3, pp. 482-489, 2004.

[24] Z. Chen, J. Zhang, and J. S. Stamler, "Identification of the enzymatic mechanism of nitroglycerin bioactivation," Proceedings of the National Academy of Sciences of the United States of America, vol. 99, no. 12, pp. 8306-8311, 2002.

[25] P. Needleman and F. E. Hunter Jr., "Effects of organic nitrates on mitochondrial respiration and swelling: possible correlations with the mechanism of pharmacologic action," Molecular Pharmacology, vol. 2, no. 2, pp. 134-143, 1966.

[26] B. Jakschik and P. Needleman, "Sulfhydryl reactivity of organic nitrates: biochemical basis for inhibition of glyceraldehyde p dehydrogenase and monoamine oxidase," Biochemical and Biophysical Research Communications, vol. 53, no. 2, pp. 539544, 1973

[27] A. Daiber, M. Oelze, M. Coldewey et al., "Oxidative stress and mitochondrial aldehyde dehydrogenase activity: a comparison of pentaerythritol tetranitrate with other organic nitrates," Molecular Pharmacology, vol. 66, no. 6, pp. 1372-1382, 2004.
[28] A. Daiber, M. Oelze, S. Sulyok et al., "Heterozygous deficiency of manganese superoxide dismutase in mice (Mn-SOD+/-): a novel approach to assess the role of oxidative stress for the development of nitrate tolerance," Molecular Pharmacology, vol. 68 , no. 3, pp. 579-588, 2005.

[29] H. Mollnau, P. Wenzel, M. Oelze et al., "Mitochondrial oxidative stress and nitrate tolerance-comparison of nitroglycerin and pentaerithrityl tetranitrate in $\mathrm{Mn}-\mathrm{SOD}+/$ - mice," $B M C$ Cardiovascular Disorders, vol. 6, article 44, 2006.

[30] J. V. Esplugues, M. Rocha, C. Nunez et al., "Complex I dysfunction and tolerance to nitroglycerin: an approach based on mitochondrial-targeted antioxidants," Circulation Research, vol. 99, no. 10, pp. 1067-1075, 2006.

[31] P. Wenzel, M. Oelze, M. Coldewey et al., "Heme oxygenase-1: a novel key player in the development of tolerance in response to organic nitrates," Arteriosclerosis, Thrombosis, and Vascular Biology, vol. 27, no. 8, pp. 1729-1735, 2007.

[32] S. Schuhmacher, P. Wenzel, E. Schulz et al., "Pentaerythritol tetranitrate improves angiotensin II-induced vascular dysfunction via induction of heme oxygenase-1," Hypertension, vol. 55, no. 4, pp. 897-904, 2010.

[33] J. Alam and J. L. Cook, "How many transcription factors does it take to turn on the heme oxygenase-1 gene?" American Journal of Respiratory Cell and Molecular Biology, vol. 36, no. 2, pp. 166-174, 2007.

[34] S. Schuhmacher, M. Oelze, F. Bollmann et al., "Vascular dysfunction in experimental diabetes is improved by pentaerithrityl tetranitrate but not isosorbide-5-mononitrate therapy," Diabetes, vol. 60, no. 10, pp. 2608-2616, 2011.

[35] S. Oberle, A. Abate, N. Grosser et al., "Heme oxygenase1 induction may explain the antioxidant profile of pentaerythrityl trinitrate," Biochemical and Biophysical Research Communications, vol. 290, no. 5, pp. 1539-1544, 2002.

[36] S. Oberle, P. Schwartz, A. Abate, and H. Schroder, "The antioxidant defense protein ferritin is a novel and specific target for pentaerithrityl tetranitrate in endothelial cells," Biochemical and Biophysical Research Communications, vol. 261, no. 1, pp. 28-34, 1999.

[37] N. Grosser, A. Hemmerle, G. Berndt et al., "The antioxidant defense protein heme oxygenase 1 is a novel target for statins in endothelial cells," Free Radical Biology and Medicine, vol. 37, no. 12, pp. 2064-2071, 2004.

[38] F. Gueler, J. K. Park, S. Rong et al., "Statins attenuate ischemia-reperfusion injury by inducing heme oxygenase- 1 in infiltrating macrophages," American Journal of Pathology, vol. 170, no. 4, pp. 1192-1199, 2007.

[39] D. Fontaine, A. Otto, J. Fontaine, and G. Berkenboom, "Prevention of nitrate tolerance by long-term treatment with statins," Cardiovascular Drugs and Therapy, vol. 17, no. 2, pp. 123-128, 2003.

[40] T. Inoue, K. Takayanagi, T. Hayashi, and S. Morooka, "Fluvastatin attenuates nitrate tolerance in patients with ischemic heart disease complicating hypercholesterolemia," International Journal of Cardiology, vol. 90, no. 2-3, pp. 181188, 2003.

[41] A. Liuni, M. C. Luca, G. Di Stolfo et al., "Coadministration of atorvastatin prevents nitroglycerin-induced endothelial dysfunction and nitrate tolerance in healthy humans," Journal of the American College of Cardiology, vol. 57, no. 1, pp. 93-98, 2011.

[42] T. Jansen, M. Hortmann, M. Oelze et al., "Conversion of biliverdin to bilirubin by biliverdin reductase contributes to endothelial cell protection by heme oxygenase-1-evidence for direct and indirect antioxidant actions of bilirubin," Journal of 
Molecular and Cellular Cardiology, vol. 49, no. 2, pp. 186-195, 2010.

[43] M. Knorr, M. Hausding, S. Kroller-Schuhmacher et al., "Nitroglycerin-induced endothelial dysfunction and tolerance involve adverse phosphorylation and S-glutathionylation of endothelial nitric oxide synthase: beneficial effects of therapy with the AT1 receptor blocker telmisartan," Arteriosclerosis, Thrombosis, and Vascular Biology, vol. 31, no. 10, pp. 2223 2231, 2011

[44] N. J. Alp, S. Mussa, J. Khoo et al., "Tetrahydrobiopterindependent preservation of nitric oxide-mediated endothelial function in diabetes by targeted transgenic GTPcyclohydrolase I overexpression," Journal of Clinical Investigation, vol. 112, no. 5, pp. 725-735, 2003.

[45] C. Antoniades, C. Cunnington, A. Antonopoulos et al., "Induction of vascular GTP-cyclohydrolase i and endogenous tetrahydrobiopterin synthesis protect against inflammationinduced endothelial dysfunction in human atherosclerosis," Circulation, vol. 124, no. 17, pp. 1860-1870, 2011.

[46] J. Xu, Y. Wu, P. Song, M. Zhang, S. Wang, and M. H. Zou, "Proteasome-dependent degradation of guanosine 5'triphosphate cyclohydrolase I causes tetrahydrobiopterin deficiency in diabetes mellitus," Circulation, vol. 116, no. 8, pp. 944-953, 2007.

[47] N. G. Abraham and A. Kappas, "Pharmacological and clinical aspects of heme oxygenase," Pharmacological Reviews, vol. 60, no. 1, pp. 79-127, 2008.

[48] M. Oppermann, V. Balz, V. Adams et al., "Pharmacological induction of vascular extracellular superoxide dismutase expression in vivo," Journal of Cellular and Molecular Medicine, vol. 13, no. 7, pp. 1271-1278, 2009.

[49] A. W. Jones, W. Durante, and R. J. Korthuis, "Heme oxygenase-1 deficiency leads to alteration of soluble guanylate cyclase redox regulation," Journal of Pharmacology and Experimental Therapeutics, vol. 335, no. 1, pp. 85-91, 2010.

[50] T. Gori and A. Daiber, "Non-hemodynamic effects of organic nitrates and the distinctive characteristics of pentaerithrityl tetranitrate," American Journal of Cardiovascular Drugs, vol. 9, no. 1, pp. 7-15, 2009.

[51] A. L. Kleschyov, M. Oelze, A. Daiber et al., "Does nitric oxide mediate the vasodilator activity of nitroglycerin?" Circulation Research, vol. 93, no. 9, pp. e104-112, 2003.

[52] T. Thum, D. Fraccarollo, S. Thum et al., "Differential effects of organic nitrates on endothelial progenitor cells are determined by oxidative stress," Arteriosclerosis, Thrombosis, and Vascular Biology, vol. 27, no. 4, pp. 748-754, 2007.

[53] J. M. DiFabio, G. R. Thomas, L. Zucco et al., "Nitroglycerin attenuates human endothelial progenitor cell differentiation, function, and survival," Journal of Pharmacology and Experimental Therapeutics, vol. 318, no. 1, pp. 117-123, 2006.

[54] H. H. Lin, Y. H. Chen, P. F. Chang, Y. T. Lee, S. F. Yet, and L. Y. Chau, "Heme oxygenase-1 promotes neovascularization in ischemic heart by coinduction of VEGF and SDF-1," Journal of Molecular and Cellular Cardiology, vol. 45, no. 1, pp. 44-55, 2008.

[55] T. Thum, D. Fraccarollo, M. Schultheiss et al., "Endothelial nitric oxide synthase uncoupling impairs endothelial progenitor cell mobilization and function in diabetes," Diabetes, vol. 56, no. 3, pp. 666-674, 2007.

[56] T. Gori, J. M. Burstein, S. Ahmed et al., "Folic acid prevents nitroglycerin-induced nitric oxide synthase dysfunction and nitrate tolerance: a human in vivo study," Circulation, vol. 104, no. 10, pp. 1119-1123, 2001.
[57] H. Ikejima, T. Imanishi, H. Tsujioka et al., "Effect of pioglitazone on nitroglycerin-induced impairment of nitric oxide bioavailability by a catheter-type nitric oxide sensor," Circulation Journal, vol. 72, no. 6, pp. 998-1002, 2008.

[58] K. Schmidt, M. Rehn, H. Stessel, G. Wolkart, and B. Mayer, "Evidence against tetrahydrobiopterin depletion of vascular tissue exposed to nitric oxide/superoxide or nitroglycerin," Free Radical Biology and Medicine, vol. 48, no. 1, pp. 145-152, 2010.

[59] T. Gori, S. Dragoni, G. Di Stolfo et al., "Tolerance to nitroglycerin-induced preconditioning of the endothelium: a human in vivo study," American Journal of Physiology, vol. 298, no. 2, pp. H340-H345, 2010.

[60] T. Gori, M. Lisi, and S. Forconi, "Ischemia and reperfusion: the endothelial perspective. A radical view," Clinical Hemorheology and Microcirculation, vol. 35, no. 1-2, pp. 31-34, 2006.

[61] T. Gori and J. D. Parker, "Nitrate-induced toxicity and preconditioning. A rationale for reconsidering the use of these drugs," Journal of the American College of Cardiology, vol. 52, no. 4, pp. 251-254, 2008.

[62] S. Dragoni, T. Gori, M. Lisi et al., "Pentaerythrityl tetranitrate and nitroglycerin, but not isosorbide mononitrate, prevent endothelial dysfunction induced by ischemia and reperfusion," Arteriosclerosis, Thrombosis, and Vascular Biology, vol. 27, no. 9, pp. 1955-1959, 2007.

[63] D. K. Das and N. Maulik, "Cardiac genomic response following preconditioning stimulus," Cardiovascular Research, vol. 70, no. 2, pp. 254-263, 2006.

[64] G. Jancso, B. Cserepes, B. Gasz et al., "Expression and protective role of heme oxygenase-1 in delayed myocardial preconditioning," Annals of the New York Academy of Sciences, vol. 1095, pp. 251-261, 2007.

[65] L. Vitek and H. A. Schwertner, "The heme catabolic pathway and its protective effects on oxidative stress-mediated diseases," Advances in Clinical Chemistry, vol. 43, pp. 1-57, 2007.

[66] D. P. Converso, C. Taille, M. C. Carreras, A. Jaitovich, J. J. Poderoso, and J. Boczkowski, "HO-1 is located in liver mitochondria and modulates mitochondrial heme content and metabolism," The FASEB Journal, vol. 20, no. 8, pp. 12361238, 2006.

[67] H. B. Suliman, M. S. Carraway, A. S. Ali, C. M. Reynolds, K. E. Welty-Wolf, and C. A. Piantadosi, "The CO/HO system reverses inhibition of mitochondrial biogenesis and prevents murine doxorubicin cardiomyopathy," Journal of Clinical Investigation, vol. 117, no. 12, pp. 3730-3741, 2007.

[68] S. Bindu, C. Pal, S. Dey et al., "Translocation of heme oxygenase-1 to mitochondria is a novel cytoprotective mechanism against non-steroidal anti-inflammatory drug-induced mitochondrial oxidative stress, apoptosis, and gastric mucosal injury," Journal of Biological Chemistry, vol. 286, no. 45, pp. 39387-39402, 2011.

[69] P. Wenzel, H. Mollnau, M. Oelze et al., "First evidence for a crosstalk between mitochondrial and NADPH oxidasederived reactive oxygen species in nitroglycerin-triggered vascular dysfunction," Antioxidants and Redox Signaling, vol. 10, no. 8, pp. 1435-1447, 2008.

[70] A. Daiber and T. Munzel, "Characterization of the antioxidant properties of pentaerithrityl tetranitrate (PETN)-induction of the intrinsic antioxidative system heme oxygenase-1 (HO-1)," Methods in Molecular Biology, vol. 594, pp. 311-326, 2010.

[71] U. Jurt, T. Gori, A. Ravandi, S. Babaei, P. Zeman, and J. D. Parker, "Differential effects of pentaerythritol tetranitrate and nitroglycerin on the development of tolerance and evidence of lipid peroxidation: a human in vivo study," Journal of the 
American College of Cardiology, vol. 38, no. 3, pp. 854-859, 2001.

[72] J. Pfeilschifter and K. F. Beck, "Nitric oxide and gene expression," in Nitric Oxide, Cell Signaling, and Gene Expression, E. Cadenas and S. Lamas, Eds., pp. 327-348, Taylor \& Francis, Boca Raton, Fla, USA, 2005.

[73] T. Thum and J. Bauersachs, "Microarray-based gene expression profiling to elucidate cellular responses to nitric oxidea review from an analytical and biomedical point of view," Journal of Chromatography B, vol. 851, no. 1-2, pp. 3-11, 2007.

[74] C. Bogdan, "Nitric oxide and the regulation of gene expression," Trends in Cell Biology, vol. 11, no. 2, pp. 66-75, 2001.

[75] R. B. Pilz and D. E. Casteel, "Regulation of gene expression by cyclic GMP," Circulation Research, vol. 93, no. 11, pp. 10341046, 2003.

[76] B. J. Buckley, Z. M. Marshall, and A. R. Whorton, "Nitric oxide stimulates Nrf2 nuclear translocation in vascular endothelium," Biochemical and Biophysical Research Communications, vol. 307, no. 4, pp. 973-979, 2003.

[77] Y. Kuwano, A. Rabinovic, S. Srikantan, M. Gorospe, and B. Demple, "Analysis of nitric oxide-stabilized mRNAs in human fibroblasts reveals HuR-dependent heme oxygenase 1 upregulation," Molecular and Cellular Biology, vol. 29, no. 10, pp. 2622-2635, 2009.

[78] C. Tassorelli and S. A. Joseph, "NADPH-diaphorase activity and Fos expression in brain nuclei following nitroglycerin administration," Brain Research, vol. 695, no. 1, pp. 37-44, 1995.

[79] C. Tassorelli, R. Greco, M. T. Armentero, F. Blandini, G. Sandrini, and G. Nappi, "A role for brain cyclooxygenase-2 and prostaglandin-E2 in migraine: effects of nitroglycerin," International Review of Neurobiology, vol. 82, pp. 373-382, 2007.

[80] R. Greco, D. Amantea, F. Blandini et al., "Neuroprotective effect of nitroglycerin in a rodent model of ischemic stroke: evaluation of Bcl-2 expression," International Review of Neurobiology, vol. 82, pp. 423-435, 2007.

[81] C. Suwattanasophon, P. Phansuwan-Pujito, and A. Srikiatkhachorn, "5-HT1B/1D serotonin receptor agonist attenuates nitroglycerin-evoked nitric oxide synthase expression in trigeminal pathway," Cephalalgia, vol. 23, no. 8, pp. 825-832, 2003.

[82] L. Prevotat, R. Filomenko, E. Solary, J. F. Jeannin, and A. Bettaieb, "Nitric oxide-induced down-regulation of $\beta$-catenin in colon cancer cells by a proteasome-independent specific pathway," Gastroenterology, vol. 131, no. 4, pp. 1142-1152, 2006.

[83] K. Szocs, B. Lassegue, P. Wenzel et al., "Increased superoxide production in nitrate tolerance is associated with $\mathrm{NAD}(\mathrm{P}) \mathrm{H}$ oxidase and aldehyde dehydrogenase 2 downregulation," Journal of Molecular and Cellular Cardiology, vol. 42, no. 6, pp. 1111-1118, 2007.

[84] E. Q. Wang, W. I. Lee, D. Brazeau, and H. L. Fung, "cDNA microarray analysis of vascular gene expression after nitric oxide donor infusions in rats: implications for nitrate tolerance mechanisms," AAPS PharmSci, vol. 4, no. 2, article E10, 2002.

[85] A. Pautz, P. Rauschkolb, N. Schmidt et al., "Effects of nitroglycerin or pentaerithrityl tetranitrate treatment on the gene expression in rat hearts: evidence for cardiotoxic and cardioprotective effects," Physiological Genomics, vol. 38, no. 2, pp. 176-185, 2009.

[86] S. Dhakshinamoorthy and A. G. Porter, "Nitric oxide-induced transcriptional up-regulation of protective genes by Nrf2 via the antioxidant response element counteracts apoptosis of neuroblastoma cells," Journal of Biological Chemistry, vol. 279, no. 19, pp. 20096-20107, 2004.

[87] X. M. Liu, K. J. Peyton, D. Ensenat et al., "Nitric oxide stimulates heme oxygenase-1 gene transcription via the Nrf2/ARE complex to promote vascular smooth muscle cell survival," Cardiovascular Research, vol. 75, no. 2, pp. 381-389, 2007.

[88] C. L. Hartsfield, J. Alam, J. L. Cook, and A. M. Choi, "Regulation of heme oxygenase-1 gene expression in vascular smooth muscle cells by nitric oxide," American Journal of Physiology, vol. 273, no. 5, part 1, pp. L980-L988, 1997.

[89] C. Bouton and B. Demple, "Nitric oxide-inducible expression of heme oxygenase- 1 in human cells. Translation-independent stabilization of the mRNA and evidence for direct action of nitric oxide," Journal of Biological Chemistry, vol. 275, no. 42, pp. 32688-32693, 2000.

[90] V. Leautaud and B. Demple, "Regulation of heme oxygenase1 mRNA deadenylation and turnover in NIH3T3 cells by nitrosative or alkylation stress," BMC Molecular Biology, vol. 8, article 116, 2007.

[91] U. Hinkelmann, N. Grosser, K. Erdmann, H. Schroder, and S. Immenschuh, "Simvastatin-dependent up-regulation of heme oxygenase-1 via mRNA stabilization in human endothelial cells," European Journal of Pharmaceutical Sciences, vol. 41, no. 1, pp. 118-124, 2010.

[92] J. D. Beckman, C. Chen, J. Nguyen et al., "Regulation of heme oxygenase-1 protein expression by miR-377 in combination with miR-217," Journal of Biological Chemistry, vol. 286, no. 5, pp. 3194-3202, 2011.

[93] C. M. Misquitta, V. R. Iyer, E. S. Werstiuk, and A. K. Grover, "The role of 3 '-untranslated region (3'-UTR) mediated mRNA stability in cardiovascular pathophysiology," Molecular and Cellular Biochemistry, vol. 224, no. 1-2, pp. 53-67, 2001.

[94] K. S. Khabar, "The AU-rich transcriptome: more than interferons and cytokines, and its role in disease," Journal of Interferon and Cytokine Research, vol. 25, no. 1, pp. 1-10, 2005.

[95] A. Hacker, S. Muller, W. Meyer, and G. Kojda, "The nitric oxide donor pentaerythritol tetranitrate can preserve endothelial function in established atherosclerosis," British Journal of Pharmacology, vol. 132, no. 8, pp. 1707-1714, 2001. 


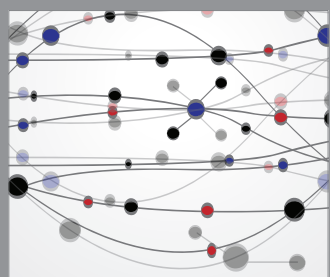

The Scientific World Journal
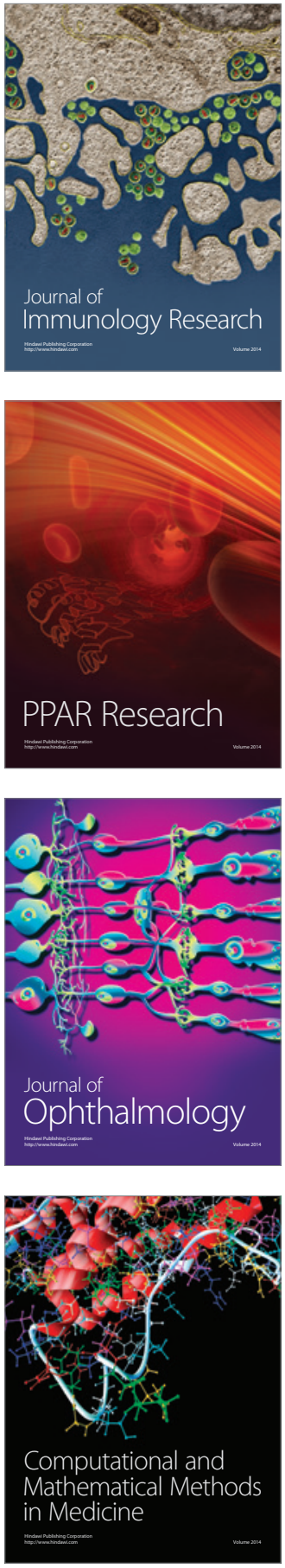

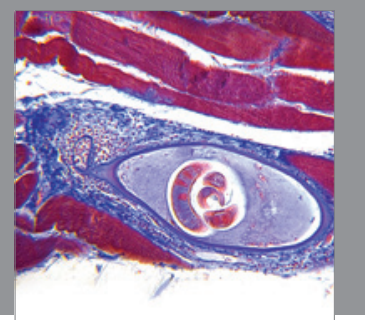

Gastroenterology

Research and Practice
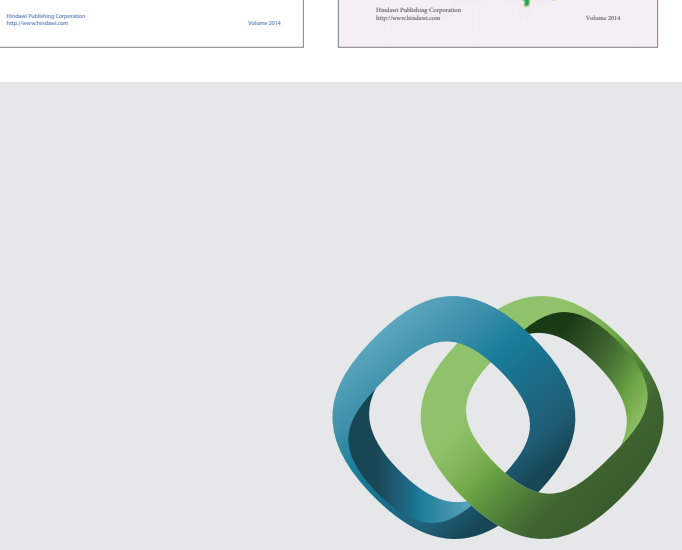

\section{Hindawi}

Submit your manuscripts at

http://www.hindawi.com
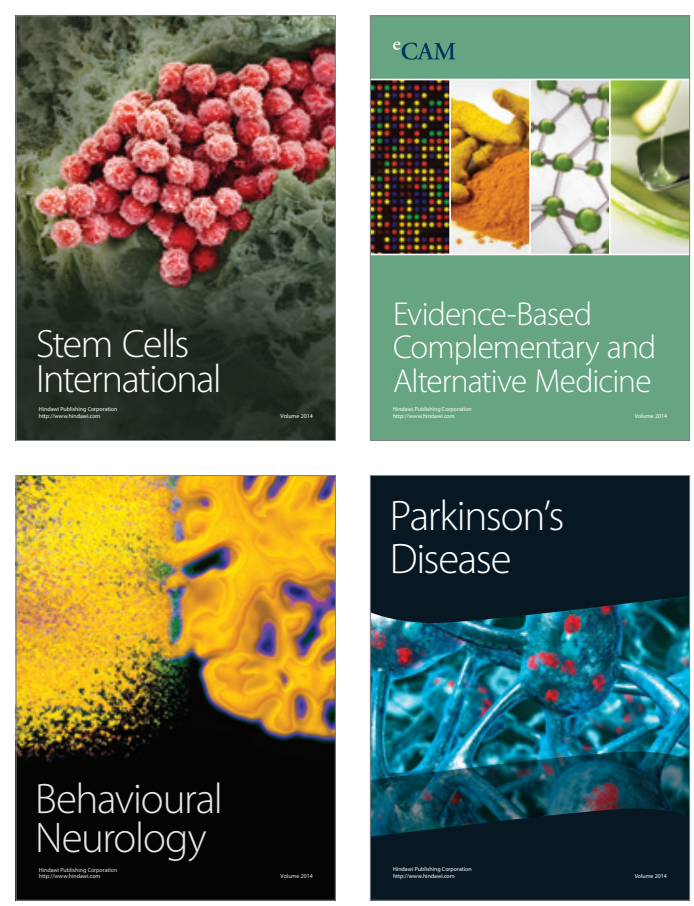

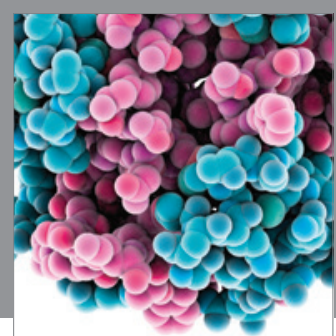

Journal of
Diabetes Research

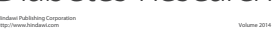

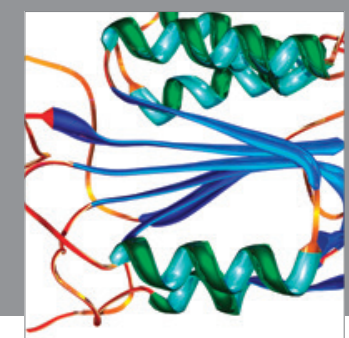

Disease Markers
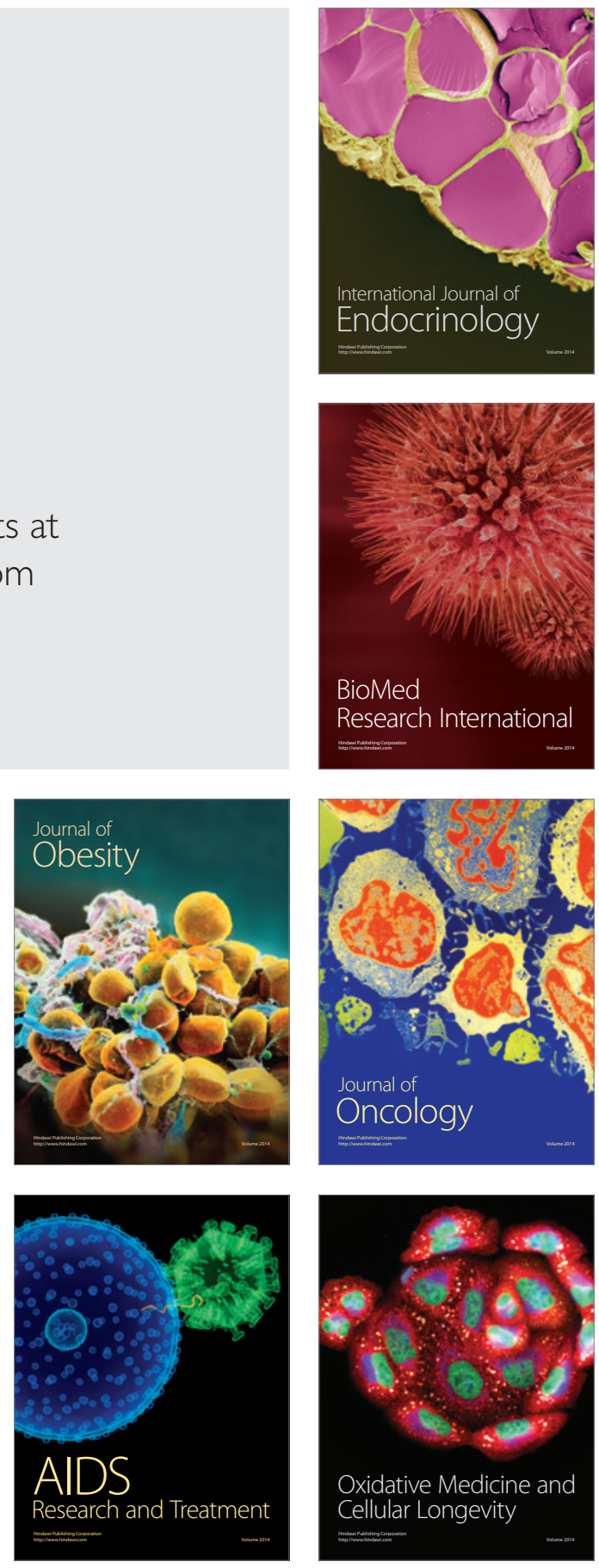